\title{
Standardizing disease-specific quality of life measures across multiple chronic conditions: development and initial evaluation of the QOL Disease Impact Scale (QDIS ${ }^{\circledR}$ )
}

\author{
John E. Ware Jr. ${ }^{1,2^{*}}$, Barbara Gandek ${ }^{1,2}$, Rick Guyer ${ }^{1}$ and Nina Deng ${ }^{2,3}$
}

\begin{abstract}
Background: To document the development and evaluation of the Quality of life Disease Impact Scale (QDIS ${ }^{\oplus}$, a measure that standardizes item content and scoring across chronic conditions and provides a summary, normbased QOL impact score for each disease.

Methods: A bank of 49 disease impact items was constructed from previously-used descriptions of health impact to represent ten frequently-measured quality of life $(\mathrm{QOL})$ content areas and operational definitions successfully utilized in generic QOL surveys. In contrast to health in general, all items were administered with attribution to a specific disease (osteoarthritis, rheumatoid arthritis, angina, myocardial infarction, congestive heart failure, chronic kidney disease (CKD), diabetes, asthma, or COPD). Responses from 5418 adults were analyzed as five disease groups: arthritis, cardiovascular, CKD, diabetes, and respiratory. Unidimensionality, item parameter and scale-level invariance, reliability, validity and responsiveness to change during 9-month follow-up were evaluated by disease group and for all groups combined using multi-group confirmatory factor analysis (MGCFA), item response theory (IRT) and analysis of variance methods. QDIS was normed in an independent chronically ill US population sample $(N=4120)$.
\end{abstract}

Results: MGCFA confirmed a 1-factor model, justifying a summary score estimated using equal parameters for each item across disease groups. In support of standardized IRT-based scoring, correlations were very high between disease-specific and standardized IRT item slopes $(r=0.88-0.96)$, thresholds $(r=0.93-0.99)$ and person-level scores $(r \geq 0.99)$. Internal consistency, test-retest and person-level IRT reliability were consistently satisfactory across groups. In support of interpreting QDIS as a disease-specific measure, in comparison with generic measures, QDIS consistently discriminated markedly better across disease severity levels, correlated higher with other disease-specific measures in cross-sectional tests, and was more responsive in comparisons of groups with better, same or worse evaluations of disease-specific outcomes at the 9-month follow-up.

Conclusions: Standardization of content and scoring across diseases was shown to be justified psychometrically and enabled the first summary measure of disease-specific QOL impact normed in the chronically ill population. This disease-specific approach substantially improves discriminant validity and responsiveness over generic measures and provides a basis for better understanding the relative QOL impact of multiple chronic conditions in research and clinical practice.

Keywords: Patient-reported outcomes, Health-related quality of life, Disease-specific measures, Multiple chronic conditions, Item response theory, Norm-based scoring, Validity, Responsiveness

\footnotetext{
* Correspondence: john.ware@jwrginc.com

1John Ware Research Group, 10 Wheeler Court, Watertown, MA 02472, USA

${ }^{2}$ Department of Quantitative Health Sciences, University of Massachusetts

Medical School, Worcester, MA, USA

Full list of author information is available at the end of the article
} 


\section{Background}

Disease-specific measures of quality of life (QOL) have the advantage of frequently being more responsive and clinically useful than generic QOL measures which do not focus on any specific condition [1-3], while generic measures have the advantage of enabling comparisons of QOL burden and treatment benefit across diseases $[4,5]$. The advantages of disease-specific measures result in part from achieving specificity by measuring the frequency and severity of specific symptoms such as joint pain in arthritis [6] or dyspnea in respiratory disease [7]. Conceptually, however, such symptoms capture QOL only to the extent that they are also quantified in terms of their impact on life or its quality [8].

To achieve the benefits of both measurement traditions, patient-reported outcome (PRO) surveys have integrated questions about specific symptoms with disease-specific and generic QOL measures [9-13]. Content from generic QOL measures has been incorporated in disease-specific measures to the point that a primary difference between them is whether survey questions make attributions to health in general, a specific component of health (e.g., physical or mental), or a specific disease. With more specific attribution, otherwise generic QOL items have been shown to differ markedly in their validity and interpretation. For example, a Sickness Impact Profile item [14] asking about "not accomplishing as much as usual at work" because of "health", modified to make attributions to "physical health" versus "emotional problems", better discriminated between physical and mental conditions in Medical Outcomes Study (MOS) surveys [15, 16]. However, lack of standardization of QOL content precludes use of disease-specific measures in making comparisons across diseases, and substantial gaps in the representation of QOL content known to be affected by specific diseases remain [17]. The content areas most often represented in widely-used generic QOL surveys are not all represented in any disease-specific survey of which we are aware. One noteworthy exception, a survey of QOL impact attributed to headache, comes close to doing so [12].

Disease-specific and generic PROs have a complimentary relationship. For example, generic measures can monitor changes in the physical functioning of patients over time in relation to population norms, regardless of the cause of any change. Disease-specific measures can help determine which conditions accounted most for a patient's limitations in physical functioning and, therefore, make PROs more useful in outcomes research, predictive studies of health care costs, and everyday clinical practice. In theory, tradeoffs between disease-specific and generic measures are unnecessary. A new approach to measurement is possible, one that quantifies the impact of each specific condition more broadly in QOL terms but also allows conditions to be compared on a common metric. This approach uniformly applies disease attributions to the same QOL content for every condition and standardizes scoring metrics across conditions. In other words, one method could achieve the advantages of both disease-specific and generic PROs. To the extent that standardized content and scoring across diseases are justified psychometrically, the new approach could also compliment generic measures in practice settings, by providing clinicians with a sound basis for comparing the relative burden of multiple chronic conditions in disease-specific QOL terms. Underlying this advance in methods are some crucial assumptions.

In pursuit of this approach, the Computerized Adaptive Assessment of Disease Impact (DICAT) project was launched with NIH support $[18,19]$. DICAT's goals were to develop a measure of disease-specific impact that was more comprehensive than existing measures and that could be standardized to enable comparisons across conditions. This paper documents the development of the Quality of life Disease Impact Scale $\left(\mathrm{QDIS}^{\circledR}\right)$, a standardized disease-specific QOL measure that can be scored in relation to norms for the chronically ill US population. It also presents results from initial tests of psychometric assumptions underlying QDIS construction and its empirical validity in comparison with generic measures.

\section{Methods}

\section{Item bank development}

QDIS was developed on the assumptions that diseasespecific attributions can improve the validity of otherwise generic QOL items enough to interpret them as diseasespecific measures and that the content of disease-specific measures can be as comprehensive as that of generic measures. Thus, the 49-item QDIS bank included item content selected from words and phrases in widely-used generic and disease-specific surveys, representing ten distinct health-related QOL domains of physical, role and social functioning, mobility, emotional distress and well-being, vitality, sleep, health outlook, cognitive functioning, and quality of life. A major modification to all QDIS items was the change in attribution to a specific disease or condition, as opposed to health in general or no attribution. For example, the QDIS item "In the past 4 weeks, how often did your [CONDITION] limit your physical activities such as walking or climbing stairs?" (where [CONDITION] was a specific disease such as angina) was nearly identical to a generic physical function item previously validated in the MOS [20] and evaluated, with others, in recent qualitative studies $[21,22]$. A second modification was to standardize all QDIS content (item stem and response categories) across diseases.

To benefit as much as possible from prior work, successfully-used descriptions of health impact and operational definitions were adapted for QDIS. One primary 
source of QDIS content and operational definitions were full-length generic surveys fielded in the Medical Outcomes Study (MOS) [16], which included items from which the 36-item MOS short-form was constructed $[15,23]$, and their predecessors as documented elsewhere [16, 24-28]. In comparison with the SF- $36^{\circ}$ Health Survey, QDIS added content capturing disease impact on cognitive function, sleep and quality of life. Another source was item content from seven scales measuring QOL impact attributed to headache pain [29] and subsequent adaptations that changed attributions from headache to other conditions [30-33]. QDIS operational definitions were matched with item content as much as possible to improve validity (e.g., behavioral performance or capacity in measuring physical functioning) and were intentionally varied to measure multiple aspects of disease impact.

Items were standardized to have the same stem structure and 5-choice categorical rating scale and a 4-week recall, the latter to achieve a better time sample of outcomes. The few exceptions were the global QOL items and alternate forms of some items included to enable a cross-walk between alternative methods. In addition to minimizing local dependence and correlated errors due to methods effects, this standardization also facilitates single-item administrations (such as on a PDA) as required for computerized adaptive administrations. Instructions, item stems and response categories were written to be understandable by nearly all US adults. The 49-item bank has a Flesch-Kincaid Grade Level of 7.3 and a Flesch Reading Ease score of 74.7, which equates to a reading level of fairly easy [34].

\section{Sampling and data collection}

Data came from Internet surveys of the US household population with oversampling of the chronically ill, fielded in 2011 in three waves (January-February, July-September, October-December). The DICAT study was approved by the New England Institutional Review Board.

Two independent DICAT samples were recruited. The first (pre-ID) sample, used in item bank development and evaluation, included panelists aged 18 and older $(N=5418)$ who previously reported being diagnosed with any of nine conditions within five disease groups: arthritis (osteoarthritis, rheumatoid), chronic kidney disease (CKD), cardiovascular disease (angina, myocardial infarction in past year, congestive heart failure), diabetes, and respiratory disease (asthma, chronic obstructive pulmonary disease). The second sample, used in QDIS norming, was a representative sample of the U.S. general population age 18 and older, who had chronic conditions in their naturally-occurring proportions; data from adults who reported one or more of 35 chronic conditions $(N=4120$ out of 5173 total) were analyzed. Panelists in both samples were recruited from the GfK (formerly Knowledge Networks (KN)) research panel of approximately 50,000 adults, which uses address-based sampling from the U.S. Postal Service's Delivery Sequence File to represent approximately $97 \%$ of U.S. households. Unlike convenience ("opt-in") panels, the KN panel is a probability-based sample, as recommended for Internet surveys [35]. It includes cell-phone only households, and panelists who do not have Internet access are provided with a computer and Internet connection [36]. Pre-ID conditions for panelists in the first sample were confirmed at the start of the DICAT survey, and pre-ID panelists were sampled to achieve at least 1000 respondents within three disease groups, with smaller targets for less prevalent diagnoses (CKD, cardiovascular).

Panelists were recruited via a routine invitation from KN. E-mail and IVR telephone reminders were sent to nonresponders. In the pre-ID sample, 9160 panelists received invitations, of whom 6828 opened the informed consent screen (consent screening rate of $74.5 \%$ ), 5585 consented, and 5418 completed surveys (survey completion rate of $97.0 \%$ [37]. Corresponding figures for the general population sample were 10,128 invites, 6433 (63.5\%) opened the informed consent screen, 5332 consented, and 5173 completed surveys $(97.0 \%)$. Responsiveness analyses used Wave 3 data from the pre-ID sample; 2816 Wave 1 pre-ID panelists were invited to complete a Wave 3 survey, of whom 2447 opened the informed consent screen (86.9\%), 2442 consented, and 2384 completed surveys (97.6 \%). By design some Wave 3 respondents did not complete a generic SF$8^{\text {nt }}$ Health Survey; a total of $N=1889$ panelists had QDIS and SF- 8 data in both Waves 1 and 3 .

Random assignment to survey protocols enabled administrations of different survey modules while controlling respondent burden (median total time $\leq 25 \mathrm{~min}$ ). For pre-ID and general population samples, the presentation of each QDIS and other items was identical and modules were administered in the following order: generic QOL measures, 35-item chronic condition checklist, 11-49 QDIS items for one pre-ID condition (pre-ID sample only) and 1-11 QDIS items for other conditions endorsed, and legacy diseasespecific measures (pre-ID sample only). A total of 4028 pre-ID Wave 1 and Wave 2 panelists completed 49 QDIS items in the same order for their pre-ID condition, while 1390 randomly chosen pre-ID Wave 2 panelists completed only 11 QDIS items for their pre-ID condition. All QDIS administrations began with the same item (everyday activities or quality of life, see Table 2). Other measures used in cross-sectional validation and responsiveness comparisons included the generic SF-8 physical (PCS) and mental (MCS) component scores, which have been shown to correlate highly with the SF-36 Health Survey PCS and MCS [23], along with widely-used disease-specific measures $[6,7,11,38-41]$ matched to each pre-ID condition (see Table 6). Internet data collection allowed data quality to be monitored in real time; accordingly, 
Table 1 Characteristics of pre-identified and general population chronically ill samples

\begin{tabular}{|c|c|c|c|c|c|c|c|}
\hline & \multicolumn{5}{|c|}{ Pre-Identified Disease Group } & \multirow{2}{*}{$\begin{array}{l}\text { Pre-Identified } \\
\text { Combined } \\
(N=5418)\end{array}$} & \multirow{2}{*}{$\begin{array}{l}\text { Gen. Pop. } \\
\text { Chronically III } \\
(N=4120)\end{array}$} \\
\hline & $\begin{array}{l}\text { Arthritis } \\
(N=1574)\end{array}$ & $\begin{array}{l}\text { CKD } \\
(N=299)\end{array}$ & $\begin{array}{l}\text { Cardiovascular } \\
(N=639)\end{array}$ & $\begin{array}{l}\text { Diabetes } \\
(N=1326)\end{array}$ & $\begin{array}{l}\text { Respiratory } \\
(N=1580)\end{array}$ & & \\
\hline \multicolumn{8}{|l|}{ Age } \\
\hline Mean (SD) & $62.1(11.2)$ & $63.5(12.8)$ & $65.7(10.7)$ & $60.3(11.9)$ & $53.0(16.1)$ & $59.5(13.7)$ & $50.9(16.0)$ \\
\hline Median & 63 & 64 & 66 & 61 & 55 & 61 & 52 \\
\hline Range & 20-93 & $18-92$ & $18-97$ & $18-92$ & $18-93$ & $18-97$ & $18-94$ \\
\hline$\%$ Male & 35.5 & 51.8 & 56.6 & 52.0 & 35.2 & 42.8 & 47.0 \\
\hline \multicolumn{8}{|l|}{ Race/Ethnicity } \\
\hline White non-Hispanic & 82.5 & 81.6 & 84.5 & 77.6 & 77.0 & 79.9 & 77.3 \\
\hline Black non-Hispanic & 6.9 & 8.0 & 5.3 & 11.1 & 7.3 & 7.9 & 8.9 \\
\hline Hispanic & 5.3 & 5.0 & 2.7 & 6.2 & 7.6 & 5.9 & 8.4 \\
\hline Other non-Hispanic & 5.3 & 5.4 & 7.5 & 5.1 & 8.1 & 6.3 & 5.4 \\
\hline \multicolumn{8}{|l|}{ Education } \\
\hline$<$ High school graduate & 2.6 & 4.7 & 5.6 & 2.6 & 3.4 & 3.3 & 7.3 \\
\hline High school graduate & 20.5 & 11.7 & 16.3 & 19.1 & 17.8 & 18.4 & 26.5 \\
\hline Some college & 34.1 & 41.8 & 41.9 & 39.7 & 38.2 & 38.0 & 31.6 \\
\hline College graduate & 42.8 & 41.8 & 36.2 & 38.6 & 40.6 & 40.3 & 34.6 \\
\hline \multicolumn{8}{|l|}{ Income } \\
\hline$<\$ 20,000$ & 11.6 & 15.1 & 14.9 & 10.6 & 13.7 & 12.5 & 13.8 \\
\hline$\$ 20,000-39,999$ & 21.6 & 24.4 & 26.8 & 21.9 & 18.7 & 21.6 & 21.4 \\
\hline$\$ 40,000-99,999$ & 47.4 & 44.8 & 47.4 & 52.0 & 48.0 & 48.6 & 41.8 \\
\hline$\$ 100,000+$ & 19.4 & 15.7 & 10.9 & 15.5 & 19.6 & 17.3 & 23.0 \\
\hline \multicolumn{8}{|l|}{ Employment Status } \\
\hline Employed & 35.9 & 23.7 & 20.0 & 43.4 & 47.0 & 38.4 & 52.4 \\
\hline Unemployed & 4.0 & 1.7 & 2.8 & 4.8 & 5.1 & 4.3 & 7.0 \\
\hline Retired due to age & 38.0 & 40.5 & 42.4 & 33.0 & 21.1 & 32.5 & 19.3 \\
\hline Disabled $^{a}$ & 12.8 & 24.4 & 26.5 & 10.2 & 12.3 & 14.3 & 7.7 \\
\hline Other ${ }^{b}$ & 8.7 & 8.7 & 7.4 & 7.7 & 13.9 & 9.8 & 13.1 \\
\hline Missing & 0.6 & 1.0 & 0.9 & 0.8 & 0.5 & 0.7 & 0.5 \\
\hline
\end{tabular}

Arthritis includes osteoarthritis $(N=1066)$ and rheumatoid arthritis $(N=508)$. Cardiovascular includes angina $(N=214)$, recent myocardial infarction $(N=98)$, and congestive heart failure $(N=327)$. Respiratory includes asthma $(N=1175)$ and COPD $(N=405)$

Abbreviations: CKD chronic kidney disease

${ }^{a}$ Retired due to disability

${ }^{\mathrm{b}}$ Homemaker, student, other

completeness of survey responses was not an issue. QDIS items had missing data rates of 0.6 to $1.4 \%$.

\section{Analyses}

Evaluation of the 49-item bank included item descriptive statistics, confirmatory factor analyses (CFA) to test the psychometric assumptions of unidimensionality underlying a one-factor model, and multi-group CFA (MGCFA) to test the equality of factor loadings and thresholds underlying the adoption of standardized scoring across diseases. As recommended [42], psychometric assumptions were first tested separately in each of the five disease groups and then for all groups combined. Because satisfying "psychometric" standards of scale construction does not guarantee improved validity for purposes of measuring diseasespecific outcomes, QDIS and generic measures were compared in cross-sectional and longitudinal tests to evaluate discriminant validity and responsiveness.

\section{Unidimensionality and item local dependence}

Based on prior research [13, 29, 43-45], a 1-factor model was hypothesized and evaluated for the 49-item QDIS item bank using CFA with a robust weighted least squares (WLSMV) estimator and Mplus [46]. To test whether items were sufficiently unidimensional, the percentage of variance accounted for by one factor was estimated, and model fit was evaluated using the following criteria: comparative fit index (CFI: $>0.95$ indicating good fit) and root 
mean square error of approximation (RMSEA: $<0.06$ recommended, although values are often higher with large samples [47]). Measurement invariance was evaluated by testing the fit of nested MGCFA models without (test of equal forms) and with (test of measurement invariance) the constraint of equal factor loadings and thresholds across groups, using the DIFFTEST option in Mplus [46] and the percentage change in CFI [48]. Plots of diseasespecific and standardized (across groups) factor loadings and thresholds also were inspected. Noteworthy residuals $(r>0.20$, absolute value) were flagged to identify any notable shared item variance not accounted for by the 1factor model which might indicate item local dependence, as in previous analyses [49].

\section{Differential item functioning}

Ordinal logistic regression (OLR) methods [50] were employed to test for uniform and non-uniform differential item functioning (DIF) for groups differing in age $(<65,65$ + ) and gender, using the R software package lordif [51]. Meaningful DIF was identified by a change in Nagelkerke's $\mathrm{R}^{2}$ (for uniform plus non-uniform DIF) $>0.03$ [52] or a proportionate change $>5 \%$ in the beta coefficients $\left(\beta_{1}\right)$ for the trait measured (disease impact) in OLR models with and without the group variable [53].

\section{Item Response Theory (IRT) modeling}

IRT parameters were estimated independently for each group (disease-specific parameters) and the combined sample (standardized parameters) using a Generalized Partial Credit Model (GPCM) [54] as in previous studies $[17,55-57]$ and Xcalibre ${ }^{\text {Tx }} 4$ software [58]. Goodness-offit was evaluated using chi-square item fit statistics [59] acknowledging that IRT models for polytomous items may misfit even when violations are very small [60]. To evaluate item-level invariance across independent groups, scatterplots for item slopes and thresholds were compared for 10 unique pairs of five disease groups using ResidPlots [61]. In addition, because insufficient item-level invariance may be without practical consequences [60] or may be offset by opposite effects [17], scale-level scores estimated using disease-specific and standardized item parameters were evaluated in each group using product-moment correlations and graphical scatterplots as in a parallel study [17].

\section{Item bank reduction and short form development}

A 25-item bank was developed from the 49-item bank for use in CAT administrations when the cost of item translations and of recording items for oral administrations are important considerations. Selection of items for the shorter bank and a 7-item short form (QDIS-7) was based on the following criteria (ordered in terms of priority): (a) comprehensive representation of content areas; (b) steep item slope; (c) incremental validity in predicting total bank theta score; (d) utilization in real-data CAT simulations of the 49-item bank [62]; (e) item information functions indicative of reliability over a wide range of theta values, and (f) item fit statistics. Content representation without redundancy was a priority. When multiple items represented the same content area and achieved nearly equal discrimination (slope) and incremental validity in predicting theta, higher rates of CAT utilization and higher item information over a wider range determined choices between them. As illustrated in Results, lack of fit in terms of traditional fit statistics was ignored in favor of item usefulness (discrimination, CAT utilization).

The 7-item static (QDIS-7) and adaptive 6-item CAT (QDIS-CAT-6) short forms were both scored using standardized IRT parameters and norm-based algorithms (see below). Because these forms were very highly correlated at baseline ( $r=0.97-0.98$ across five disease groups) and yielded virtually identical results in cross-sectional tests of discriminant validity, results are reported for QDIS-7. Baseline results for QDIS-CAT-6 are reported in Additional file 1: Table S1 and Additional file 2: Table S2.

\section{Reliability}

IRT estimates of the precision of scores at the personlevel were compared across severity levels (none/mild, moderate, severe/very severe). At the group-level, internal consistency reliability (Cronbach's alpha (1951) [63]) and test-retest reliability were estimated. Testretest reliability was estimated using intraclass correlation coefficients (ICC) in a sample of Wave 2 panelists including approximately equal numbers from each disease group and severity level, who completed a second QDIS survey within two weeks.

\section{Validity}

To test the hypothesis that changing item attributions from health in general to a specific disease improves the validity of QDIS as a disease-specific measure, oneway analyses of variance (ANOVA) compared scores for QDIS and generic SF-8 measures across identical groups reporting different severity levels within each disease. For the combined pre-ID groups, sample sizes were sufficient for ANOVAs across all five severity levels. The ratio of F-ratios [64] was used to calculate relative validity (RV) and differences in RV were tested for significance as documented elsewhere [65]. We hypothesized that QDIS-7 would discriminate across disease severity groups better than generic measures. In addition, product-moment correlations were estimated to test the hypothesis that correlations with legacy disease-specific QOL measures would be higher for QDIS than for generic SF-8 measures. 


\section{Responsiveness}

To extend initial tests to include responsiveness, analysis of variance (ANOVA) compared self-evaluated transition (SET) groups in terms of change scores (9-month followup minus baseline) for QDIS and generic SF-8 measures. SET groups were formed from responses (much better, somewhat better, about the same, somewhat worse, much worse) to the question "Compared to 9 months ago, how much better or worse is your $<$ DISEASE $>$ now?", where DISEASE was the pre-ID condition. Because simulation studies showed that more reliable scores were most useful for the more severely chronically ill, Wave 3 QDIS scores were estimated from a single-item (QL1) supplemented by a 1-9 item CAT only for those with severe QOL impact (QL1 score of "a lot" or "extremely") [66]. QDIS scores estimated using this method had a high correlation $(r=0.90)$ with the static QDIS-7 and nearly identical means (50.03 vs 49.97, respectively, for QDIS-7 and adaptive CAT) in evaluations of Wave 1 data. ANOVA F-statistics for Wave 3 SET groups were compared using RV estimates as above [65]. Because groups were defined based on evaluations of change in the pre-ID condition, we hypothesized that QDIS-7 would be more responsive than generic SF-8 measures. Results are reported here for all conditions combined.

\section{Norm-based T-score transformation}

IRT-calibrated QDIS scores were transformed to have a mean of 50 and standard deviation (SD) of 10 using a linear T-score transformation of scores for all US general population sample respondents reporting any chronic condition $(N=4120)$. A higher score indicates greater disease impact (worse health). Independent observations, one per person, were weighted using $\mathrm{KN}$-derived sampling weights to adjust the sample to the demographic distribution of the December 2010 Current Population Survey [67]. Normbased estimates of central tendency, variability and percentile ranks for QDIS-7 were examined. For the combined pre-ID groups, sample sizes were sufficient to estimate norms for each of five severity levels.

\section{Results}

\section{Sample characteristics}

Characteristics of the pre-identified disease samples and chronically ill norming sample are summarized in Table 1. Except for the respiratory group, pre-ID samples tended to be older than the normative sample. The latter sample was also more likely than the pre-ID samples to be employed, but was less highly educated on average. Other characteristics were similar. The characteristics of the subset of pre-ID respondents followed longitudinally did not materially differ from those documented in Table 1.

\section{Item descriptive statistics}

Table 2 summarizes item wording, content classifications, sample sizes, item-level descriptive statistics and other results (discussed below) for the combined pre-ID sample. N for most items differed only slightly $(N=3995-4044)$; exceptions included the global quality of life (QL1) and 10 other items randomly administered more often $(N=$ 5372-5399). Underlying consistently low means were large proportions $(39-82 \%$, median $=60 \%)$ endorsing the lowest impact response category.

\section{Unidimensionality and item local dependence}

In support of a generalizable 1-factor model, one dominant factor explaining $80-86 \%$ (median $=84 \%$ ) of the total variance was observed across the five disease groups. Item factor loadings were consistently very high in the combined sample $(0.81-0.96$; median $=0.92)$ and each disease group (Table 3). The CFI was satisfactory in all five disease groups (0.979-0.991) and combined sample (0.982), and the RMSEA was acceptable (0.058-0.077 across diseases; 0.074 in combined sample). Fit of the equal form $\left(\chi^{2}(5635)=20,023.4, \mathrm{CFI}=0.987\right.$, RMSEA $=$ 0.064 (90\% CI 0.063,0.065)) and measurement invariance $\left(\chi^{2}(6411)=20,927.7, C F I=0.987\right.$, RMSEA $=0.060$ $(0.059,0.061))$ multi-group CFA models was satisfactory. While the Mplus DIFFTEST for the two models was significant $\left(\chi_{\text {diff }}^{2}(776)=2583.5, p<0.0001\right)$, it is known to be sensitive to sample size [48] and the CFI did not differ (to the nearest thousandth) between the two models. Further, examination of modification indices did not support respecification of the model. Accordingly, the 1-factor solution was accepted across disease groups. Almost no evidence of item local dependence was observed among 1176 residual correlations in each of the five groups and combined sample (total of 7056 residuals); only one residual correlation $(\mathrm{HO} 2 / \mathrm{HO} 36, r=0.202)$ in one disease (CKD) exceeded 0.20. Thus, no items were eliminated from the 49 -item bank.

\section{Differential item functioning}

There was no noteworthy DIF by age or gender. The median change in Nagelkerke's $R^{2}$ was $\leq 0.001$ across items for both age and gender and the highest $\Delta R^{2}$ was 0.006 , well below the threshold $\Delta \mathrm{R}^{2}$ of 0.03 . Similarly, the median percentage increase in $\beta_{1}$ was $<0.3 \%$ for both age and gender and the maximum increase was $3.3 \%$, below the threshold of $5 \%$.

\section{IRT and other item-level properties}

Table 2 summarizes IRT and other item-level properties for all 49 items, including IRT slopes and factor loadings, which are directly related [42]. It identifies $(* *)$ seven items chosen for QDIS-7 with the following abbreviated item content (content area designation in parentheses): 
Table 2 Item content and statistics, 49-item disease-specific QOL impact bank

\begin{tabular}{|c|c|c|c|c|c|c|c|c|c|c|}
\hline Order $^{a}$ & Area $^{b}$ & Abbreviated Content $^{c}$ & $\mathrm{~N}$ & Mean (SD) & $r^{d}$ & $a^{e}$ & b Range ${ }^{e}$ & $\mathrm{Fit}^{\mathrm{f}}$ & Imax at $\Theta^{g}$ & $C A T^{\prime}$ \\
\hline $1^{* *}$ & $\mathrm{QL}$ & Everyday activity, QOL ${ }^{\mathrm{i}}$ & 5399 & $1.80(1.04)$ & .956 & 3.55 & $0.18-2.11$ & 191.9 & $6.26(1.20)$ & 100 \\
\hline 44 & QL & Activity enjoyment life $e^{i}$ & 4044 & $1.79(1.03)$ & .946 & 2.63 & $0.20-2.28$ & 151.0 & $4.20(1.10)$ & 0 \\
\hline $2^{* *}$ & $\mathrm{HO}$ & Worry health future & 5372 & $2.11(1.13)$ & .844 & 1.49 & $-0.10-1.86$ & 371.9 & $1.90(1.35)$ & 42 \\
\hline $36^{*}$ & $\mathrm{HO}$ & Concern worry & 4022 & $1.90(1.08)$ & .868 & 1.84 & $0.13-1.97$ & 284.2 & $2.65(1.55)$ & 28 \\
\hline $10^{* *}$ & PF & Usual physical activities & 4019 & $1.96(1.12)$ & .920 & 3.10 & $0.00-1.93$ & 158.2 & $4.76(1.45)$ & 55 \\
\hline $3^{*}$ & PF & Physical activity walking & 5386 & $1.95(1.20)$ & .876 & 2.20 & $0.25-1.64$ & 148.5 & $4.11(1.15)$ & 0 \\
\hline $47^{*}$ & $M B$ & Stay inside house & 4008 & $1.57(1.04)$ & .894 & 2.41 & $0.87-1.94$ & 132.5 & $5.60(1.20)$ & 0 \\
\hline $27^{* *}$ & $\mathrm{RL}$ & Work daily activities & 4015 & $1.87(1.09)$ & .964 & 5.30 & $0.08-1.89$ & 114.4 & $9.67(1.40)$ & 64 \\
\hline $5^{*}$ & $\mathrm{RL}$ & Everyday activities & 5381 & $1.77(1.06)$ & .957 & 4.67 & $0.26-1.96$ & 101.6 & $8.64(1.50)$ & 41 \\
\hline $15^{*}$ & $\mathrm{RL}$ & Get done work home & 4026 & $1.91(1.14)$ & .940 & 3.88 & $0.11-1.83$ & 123.6 & $6.97(1.50)$ & 14 \\
\hline $17^{*}$ & $\mathrm{RL}$ & Cancel work activity & 4015 & $1.42(0.85)$ & .921 & 3.47 & $0.88-2.17$ & 71.9 & $7.46(1.95)$ & 2 \\
\hline $23^{*}$ & $\mathrm{RL}$ & Limited usual activities & 4006 & $1.77(1.04)$ & .948 & 4.50 & $0.20-1.97$ & 89.2 & $8.70(1.65)$ & 14 \\
\hline $26^{*}$ & $\mathrm{RL}$ & Accomplished less & 5395 & $1.97(1.16)$ & .937 & 3.88 & $0.07-1.78$ & 85.9 & $6.94(1.40)$ & 28 \\
\hline $30^{*}$ & RL & Leisure activities & 4017 & $1.35(0.75)$ & .873 & 2.47 & $1.05-2.49$ & 152.9 & $4.35(2.15)$ & $<1$ \\
\hline $33^{*}$ & $\mathrm{RL}$ & Productive work other & 4012 & $1.54(1.00)$ & .945 & 4.12 & $0.72-1.96$ & 44.9 & $9.81(1.00)$ & 26 \\
\hline $49^{*}$ & $\mathrm{RL}$ & Daily work in and out & 3995 & $1.84(1.09)$ & .954 & 4.52 & $0.14-1.88$ & 101.5 & $8.73(1.60)$ & 34 \\
\hline 8 & $\mathrm{RL}$ & Daily tasks help & 4020 & $1.72(1.06)$ & .856 & 1.93 & $0.55-1.94$ & 183.1 & $3.37(1.35)$ & 0 \\
\hline 13 & $\mathrm{RL}$ & Usual daily activities ${ }^{j}$ & 4020 & $1.73(1.01)$ & .941 & 4.14 & $0.25-2.14$ & 107.0 & $7.12(1.30)$ & 0 \\
\hline 19 & $\mathrm{RL}$ & Stop work other activity & 4012 & $1.75(1.02)$ & .911 & 3.09 & $0.27-2.05$ & 89.1 & $5.38(1.75)$ & 0 \\
\hline 35 & $\mathrm{RL}$ & Simple tasks hard & 4006 & $1.81(1.08)$ & .923 & 3.58 & $0.22-1.93$ & 104.6 & $6.48(1.60)$ & 0 \\
\hline 38 & $\mathrm{RL}$ & Keep from traveling & 4017 & $1.46(0.97)$ & .916 & 2.42 & $1.11-1.95$ & 177.0 & $6.32(1.30)$ & 0 \\
\hline 41 & RL & Restrict recreational & 4014 & $1.48(0.90)$ & .897 & 2.64 & $0.87-2.17$ & 122.5 & $5.04(1.20)$ & 0 \\
\hline 42 & RL & Cut down amount time & 4011 & $1.68(1.04)$ & .942 & 3.97 & $0.43-1.97$ & 72.7 & $7.73(1.70)$ & $<1$ \\
\hline $6^{* *}$ & SA & Social family friends & 5383 & $1.56(0.96)$ & .950 & 4.56 & $0.57-2.04$ & 107.1 & $9.69(1.75)$ & 30 \\
\hline $37^{*}$ & SA & Enjoying social activities & 4007 & $1.60(0.98)$ & .945 & 4.34 & $0.52-2.08$ & 93.3 & $8.29(1.65)$ & 19 \\
\hline $45^{*}$ & SA & Hard to get along with & 4006 & $1.52(0.87)$ & .853 & 2.05 & $0.75-2.43$ & 208.3 & $3.26(1.65)$ & $<1$ \\
\hline 9 & SA & Enjoyment family friends & 4020 & $1.63(0.98)$ & .915 & 3.05 & $0.50-2.19$ & 93.0 & $5.16(0.90)$ & 0 \\
\hline 14 & SA & Avoid social activities & 5399 & $1.55(0.97)$ & .938 & 3.59 & $0.68-2.12$ & 67.9 & $7.52(1.00)$ & 0 \\
\hline 21 & SA & Uncomfortable people & 4015 & $1.43(0.85)$ & .890 & 2.57 & $0.93-2.09$ & 135.7 & $5.54(1.85)$ & 0 \\
\hline 32 & SA & Travel take trip & 4012 & $1.52(1.02)$ & .915 & 2.48 & $0.98-1.82$ & 75.8 & $6.53(1.30)$ & 0 \\
\hline 40 & SA & Family social leisure ${ }^{k}$ & 4015 & $1.40(0.80)$ & .920 & 3.33 & $0.92-2.60$ & 81.8 & $6.73(1.10)$ & 1 \\
\hline $4^{* *}$ & FT & Worn out, tired & 5384 & $1.94(1.13)$ & .923 & 3.41 & $0.06-1.81$ & 96.5 & $6.17(1.45)$ & 19 \\
\hline $28^{*}$ & FT & Bed most of day & 4018 & $1.30(0.73)$ & .878 & 2.37 & $1.34-2.42$ & 124.8 & $5.23(1.60)$ & $<1$ \\
\hline 18 & FT & Need lie down rest & 4012 & $1.92(1.12)$ & .884 & 2.44 & $0.16-1.92$ & 124.9 & $3.71(0.55)$ & 0 \\
\hline 46 & FT & Too tired to work & 4007 & $1.70(0.98)$ & .932 & 4.01 & $0.26-2.22$ & 107.4 & $6.70(1.35)$ & $<1$ \\
\hline $20^{*}$ & SL & Good night sleep & 5387 & $1.94(1.14)$ & .810 & 1.52 & $0.31-1.86$ & 294.0 & $2.27(1.15)$ & 26 \\
\hline $11^{* *}$ & EM & Frustrated fed up & 4011 & $2.03(1.21)$ & .871 & 1.99 & $0.14-1.74$ & 209.3 & $3.12(0.70)$ & 36 \\
\hline $7^{*}$ & EM & Bothered emotionally & 5378 & $1.67(1.00)$ & .906 & 2.04 & $0.53-2.00$ & 117.4 & $3.71(1.60)$ & 0 \\
\hline $16^{*}$ & EM & Interest enjoyment & 4018 & $1.81(1.07)$ & .940 & 4.26 & $0.20-2.01$ & 110.6 & $7.19(0.60)$ & 17 \\
\hline 22 & EM & Losing control life & 4006 & $1.56(0.97)$ & .898 & 2.35 & $0.78-1.99$ & 89.0 & $4.40(1.70)$ & 0 \\
\hline 24 & EM & Tense feel anxious & 4007 & $1.67(0.99)$ & .895 & 2.37 & $0.46-2.07$ & 107.1 & $4.07(1.70)$ & 0 \\
\hline 29 & EM & Fed up frustrated ${ }^{j}$ & 4032 & $1.68(0.99)$ & .895 & 2.39 & $0.39-2.14$ & 167.8 & $4.29(1.45)$ & 0 \\
\hline 31 & EM & Letting others down & 4019 & $1.58(1.03)$ & .914 & 2.86 & $0.78-1.89$ & 64.1 & $6.42(1.05)$ & 0 \\
\hline 34 & EM & Angry act irritable & 4001 & $1.63(0.98)$ & .885 & 2.09 & $0.61-2.03$ & 111.8 & $3.71(1.65)$ & 0 \\
\hline
\end{tabular}


Table 2 Item content and statistics, 49-item disease-specific QOL impact bank (Continued)

\begin{tabular}{lllllllllll}
\hline 39 & EM & Feel desperate & 4009 & $1.38(0.82)$ & .904 & 2.43 & $1.08-2.25$ & 114.5 & $5.25(1.60)$ & 0 \\
43 & EM & Depressed sad & 5388 & $1.62(0.99)$ & .911 & 2.04 & $0.71-1.98$ & 134.1 & $3.84(1.50)$ & 0 \\
$25^{*}$ & CG & Difficult to focus & 4009 & $1.53(0.89)$ & .921 & 3.38 & $0.60-2.20$ & 91.7 & $6.63(1.95)$ & $<1$ \\
12 & CG & Focus on work & 4010 & $1.74(1.02)$ & .927 & 3.68 & $0.29-2.09$ & 51.6 & $6.24(1.70)$ & 0 \\
48 & CG & Ability to concentrate & 4004 & $1.51(0.86)$ & .923 & 3.66 & $0.60-2.36$ & 69.3 & $6.48(2.05)$ & 3 \\
\hline
\end{tabular}

Oariginal order of administration in 49-item bank. ${ }^{*}$ In 25 -item bank. ${ }^{* *}$ In 25 -item bank and 7-item short-form

${ }^{b}$ Content area: $Q L=$ quality of life, $H O=$ health outlook, $P F=$ physical functioning, $M B=$ mobility, $R L=$ role functioning, $S A=$ social activity, $F T=$ fatigue, $S L=$ sleep, $E M=$ emotional, $C G=$ cognitive

${ }^{\mathrm{C}}$ All items used 5-choice (Never-Very often) categorical rating scale except: ${ }^{\mathrm{i}} 5$-choice (Not at all-Extremely) scale; ${ }^{\mathrm{j}}$ Cross-calibration item used 5-choice (None-All of the time) and (Never-Very often) scales in different waves; ${ }^{k}$ Item used 5-choice (Never-Always) scale

${ }^{\mathrm{d}}$ Correlation with factor in 1-factor confirmatory factor analysis, all diseases combined $(N=3152)$

eSlope (a) and range of thresholds (b) in IRT model, all diseases combined

${ }^{\mathrm{f}} \mathrm{S}-X^{2}$ fit statistic, values above 118.75 are significant at a .05 level

${ }^{9}$ Imax at $\Theta$ is maximum of the item information function (first number) at a particular theta (number in parentheses)

hercentage of times item utilized in 6-item real-data CAT simulation using 49-item bank. Item QL1 was the start item for the CAT

everyday activities or quality of life (QL), worry about health in future $(\mathrm{HO})$, limited in usual physical activities $(\mathrm{PF})$, difficulty in work or daily activities (RL), limited in usual social activities with family, friends or others (SA), worn out or tired (FT), and frustrated or fed up (EM). Table 2 also identifies 25 items recommended for use in CAT administrations.

Item thresholds were most often positive due to skewness and were consistently ordinal for each item (data not reported). Item slopes and CAT utilization agreed considerably, while item fit and CAT utilization tended to disagree; for example, only one of 10 best fitting items was in the top 10 in CAT utilization and five of the latter were among the 10 worst fitting items. The first item in Table 2, QL1, was selected as the first item for QDIS-7 and CAT administrations based on face validity ("everyday activity" and "quality of life" content), a wide range of thresholds, one of the least skewed response distributions, and a very high CFA loading, even though it had a lower slope than many items. Items chosen for QDIS-7 generally included the best item from each of the seven represented content areas in regressions testing incremental validity in relation to the total bank theta score. One exception was the QDIS-7 role functioning item, which was the second best predictor from that content area but was selected because it had much higher CAT utilization. If based entirely on

Table 3 Summary of item-level CFA and IRT evaluations by disease group and all diseases combined and disease-specific versus standardized inter-scale correlations ${ }^{a}$

\begin{tabular}{|c|c|c|c|c|c|c|c|c|c|c|}
\hline \multirow[t]{2}{*}{ Disease } & \multicolumn{6}{|c|}{ Confirmatory Factor Analysis } & \multicolumn{2}{|c|}{ IRT parameters } & \multirow{2}{*}{$\begin{array}{l}\text { Item } r \text { with } \\
\text { theta score }\end{array}$} & \multirow{2}{*}{$\begin{array}{l}\text { Inter-scale } \\
\text { correlations }\end{array}$} \\
\hline & $x^{2}$ & df & $\mathrm{CFI}$ & RMSEA (90 \% Cl) & Factor Loadings ${ }^{b}$ & Residuals ${ }^{c}$ & Slopes & Thresholds & & \\
\hline \multirow[t]{2}{*}{ Arthritis } & 7037 & 1127 & 0.979 & 0.077 & 0.91 & 0.026 & 2.58 & 0.99 & 0.76 & 0.9996 \\
\hline & & & & $(0.076-0.079)$ & $0.74-0.94$ & $0.00-0.143$ & $1.18-4.02$ & $-0.83-2.72$ & $0.59-0.86$ & \\
\hline \multirow[t]{2}{*}{ CKD } & 1865 & 1127 & 0.991 & 0.058 & 0.93 & 0.026 & 3.55 & 1.36 & 0.76 & 0.9983 \\
\hline & & & & $(0.053-0.062)$ & $0.76-0.97$ & $0.00-0.202$ & $1.29-5.94$ & $-0.24-2.38$ & $0.62-0.83$ & \\
\hline \multirow[t]{2}{*}{ Cardiovascular } & 3658 & 1127 & 0.987 & 0.069 & 0.92 & 0.022 & 3.13 & 1.18 & 0.75 & 0.9998 \\
\hline & & & & $(0.067-0.072)$ & $0.81-0.96$ & $0.00-0.141$ & $1.62-5.51$ & $-0.20-2.71$ & $0.59-0.86$ & \\
\hline \multirow[t]{2}{*}{ Diabetes } & 3991 & 1127 & 0.985 & 0.061 & 0.91 & 0.027 & 2.98 & 1.85 & 0.70 & 0.9992 \\
\hline & & & & $(0.059-0.063)$ & $0.81-0.97$ & $0.00-0.186$ & $1.36-6.05$ & $-0.29-2.99$ & $0.51-0.81$ & \\
\hline \multirow[t]{2}{*}{ Respiratory } & 4847 & 1127 & 0.990 & 0.060 & 0.92 & 0.021 & 3.13 & 1.50 & 0.75 & 0.9999 \\
\hline & & & & $(0.058-0.061)$ & $0.84-0.97$ & $0.00-0.124$ & $1.64-5.87$ & $0.10-2.67$ & $0.58-0.86$ & \\
\hline \multirow[t]{2}{*}{ Combined } & 20,669 & 1127 & 0.982 & 0.074 & 0.92 & 0.023 & 3.05 & 1.34 & 0.74 & - \\
\hline & & & & $(0.073,0.075)$ & $0.81-0.96$ & $0.00-0.158$ & $1.49-5.30$ & $-0.10-2.60$ & $0.58-0.85$ & \\
\hline
\end{tabular}

Abbreviations: $X^{2}$ chi-square test of model fit, $d f$ degrees of freedom, CFI comparative fit index, RMSEA root mean square error of approximation, CKD chronic kidney disease

${ }^{a}$ All entries are median on first line and minimum-maximum on second line unless noted

b Loadings from the completely standardized CFA solution for each disease (rows 1-5) or all diseases combined (row 6)

'Absolute value of residual correlations after controlling for single factor for each disease (rows 1-5) or all diseases combined (row 6)

${ }^{d}$ Correlation between person-level item scores and total bank theta scores for each disease (rows 1-5) or all diseases combined (row 6 )

${ }^{\text {e}}$ Correlation between person-level total bank theta scores estimated using disease-specific and standardized item parameters 
item-level fit ("Fit" in Table 2), most QDIS-7 items would not have been chosen for that static short-form. It is noteworthy that "misfitting" (by traditional standards) items often had very high factor loadings, were among the best predictors of the theta score, and were among the items most often utilized by CAT.

Medians and ranges of disease-specific and standardized (combined) QDIS item slopes were very similar and highly correlated $(r=0.88-0.96)$ as were threshold parameters $(r=0.93-0.99)$ across disease groups (Table 3, Additional file 3: Figure S1 and Additional file 4: Figure S2). This pattern was confirmed across all 10 pairs of slopes $(r$ $=0.79-0.89)$ and thresholds $(r=0.90-0.98)$ estimated independently for the five disease groups (Additional file 5: Table S3). Median item-theta score correlations were very high ( $r=0.70-0.76$ across disease groups), and their ranges also were similar across groups (Table 3 ). As shown in the plots in Additional file 3: Figure S1 and Additional file 4: Figure S2, estimates of thresholds were more robust than slopes across standardized and disease-specific estimates but both demonstrated substantial linearity.

\section{Person-level scale scores}

Scale-level (theta) scores estimated using standardized and disease-specific item parameters were very highly correlated $(r>0.99)$ (Table 3) and showed near perfect linearity in plots for each of the five groups (Additional file 6: Figure S3). These results support the notion that any differences between disease-specific and standardized item parameters affecting scale-level scores in one direction were offset by differences in other items in the opposite direction.

\section{Reliability}

Internal consistency reliability was consistently high for QDIS-7 scores (alpha $=0.91-0.94)$ across diseases (Table 4). The percentages of person-level IRT reliability estimates exceeding 0.90 were very high $(72-100 \%$, median $=93 \%)$ for the moderate and severe groups, for whom precision is most important clinically, but lower (34-60 \%) for none/ mild groups. For the 376 panelists completing QDIS-7 retest surveys within 5-14 days (median $=8$ days) and reporting their health was the same, test-retest reliability was satisfactory (ICC $=0.83-0.91$ across groups).

\section{Validity}

In cross-sectional tests of validity in discriminating across severity levels, QDIS means increased progressively with greater disease severity in all five diseases (Table 5). In support of the hypothesis that disease-specific QDIS measures were more valid than generic measures, a significantly $(p<0.05)$ higher F-ratio for mean differences across severity levels was observed for QDIS-7 $(\mathrm{RV}=1.0)$ in comparison with SF-8 physical and mental measures ( $R V=$ $0.05-0.65$, median $=0.18$ ) in every disease group. Increases in both mean severity level separations and reductions in within group variances for QDIS-7 contributed to these results. The orders of magnitude of F-statistics for QDIS were markedly larger ( 1.5 to 20 times, median $=5.6$ times) than those observed for generic measures in the same comparisons. In tests of convergent validity, correlations between QDIS-7 scores and corresponding legacy QOL measures for the same disease were very high $(r=0.71-$ 0.83) (Table 6). A similar pattern of moderate to high correlations $(r=0.54-0.74$, median $=0.66)$ was observed between QDIS-7 and corresponding disease severity

Table 4 Comparison of QDIS-7 means and reliability estimates, five disease groups

\begin{tabular}{|c|c|c|c|c|c|c|c|}
\hline \multirow[t]{2}{*}{ Disease } & \multirow[t]{2}{*}{ Mean $(S D)^{a}$} & \multicolumn{4}{|c|}{$\%$ with IRT Reliability $\geq 0.90$ by Severity Level ${ }^{b}$} & \multirow[t]{2}{*}{ Alpha $^{c}$} & \multirow{2}{*}{$\begin{array}{l}\text { Test-retest } \\
\text { reliability }^{d}\end{array}$} \\
\hline & & Mild & Moderate & Severe & Total & & \\
\hline \multirow[t]{2}{*}{ Arthritis } & $54.24(8.72)$ & $(N=718)$ & $(N=587)$ & $(N=231)$ & $(N=1536)$ & .94 & .88 \\
\hline & & 60.5 & 93.5 & 95.7 & 78.4 & & \\
\hline \multirow[t]{2}{*}{ CKD } & $48.97(9.17)$ & $(N=200)$ & $(N=61)$ & $(N=36)$ & $(N=297)$ & .94 & .91 \\
\hline & & 34.5 & 82.0 & 94.4 & 51.5 & & \\
\hline \multirow[t]{2}{*}{ Cardiovascular } & $51.65(9.87)$ & $(N=483)$ & $(N=112)$ & $(N=36)$ & $(N=631)$ & .94 & .90 \\
\hline & & 55.5 & 95.5 & 91.7 & 64.7 & & \\
\hline \multirow[t]{2}{*}{ Diabetes } & $47.60(7.75)$ & $(N=921)$ & $(N=329)$ & $(N=63)$ & $(N=1313)$ & .91 & .83 \\
\hline & & 38.6 & 72.0 & 100.0 & 49.9 & & \\
\hline \multirow[t]{2}{*}{ Respiratory } & $48.45(9.45)$ & $(N=1152)$ & $(N=306)$ & $(N=112)$ & $(N=1570)$ & .94 & .88 \\
\hline & & 36.4 & 87.3 & 93.8 & 50.4 & & \\
\hline
\end{tabular}

\section{Abbreviations: CKD chronic kidney disease}

${ }^{a}$ Analysis of variance indicated that QDIS-7 group means differed across disease groups $\left(F_{(4,5413)}=152.1, p<0.0001\right)$. QDIS-7 scores have mean $=50, S D=10$ in chronically-ill US general population; higher scores equal worse health

${ }^{b}$ Percent with IRT estimated reliability $\geq 0.90$. Severity defined as Mild (None, Mild), Moderate, or Severe (Severe, Very Severe) in response to item How would you rate the severity of your < condition $>$ in the past 4 weeks?

Internal consistency reliability for arthritis $(N=1113)$, CKD $(N=261)$, cardiovascular $(N=578)$, diabetes $(N=857)$ and respiratory groups $(N=1156)$

${ }^{d}$ Intraclass correlation coefficient $\left(\operatorname{ICC}_{(3,1)}\right)$ for arthritis $(N=109)$, CKD $(N=37)$, cardiovascular $(N=63)$, diabetes $(N=75)$ and respiratory groups $(N=92)$ 
Table 5 Comparison of relative validity (RV) of QDIS-7 and generic measures in discriminating across severity levels, five disease groups

\begin{tabular}{|c|c|c|c|c|c|c|}
\hline \multirow{2}{*}{$\begin{array}{l}\text { Disease/ } \\
\text { Measure }\end{array}$} & \multicolumn{3}{|c|}{ Mean (SD) by Self-Evaluated Severity ${ }^{a}$} & \multirow[t]{2}{*}{ F-ratio } & \multirow[t]{2}{*}{$\mathrm{RV}^{\mathrm{b}}$} & \multirow[t]{2}{*}{$95 \% \mathrm{Cl}^{\mathrm{c}}$} \\
\hline & Mild & Moderate & Severe & & & \\
\hline Arthritis & $(N=688)$ & $(N=564)$ & $(N=214)$ & & & \\
\hline QDIS-7 $7^{d}$ & $49.2(6.88)$ & $57.4(5.83)$ & 64.9 (5.81) & 586.27 & 1.00 & \\
\hline SF-8 PCS & $48.1(7.60)$ & 40.9 (8.65) & $31.2(8.22)$ & 383.73 & 0.65 & $(0.56,0.76)$ \\
\hline SF-8 MCS & $51.8(8.08)$ & $48.8(10.19)$ & $44.7(11.40)$ & 49.19 & 0.08 & $(0.05,0.12)$ \\
\hline CKD & $(N=189)$ & $(N=56)$ & $(N=33)$ & & & \\
\hline QDIS-7 & $44.7(6.96)$ & $53.3(7.72)$ & $61.3(8.40)$ & 87.99 & 1.00 & \\
\hline SF-8 PCS & $42.2(11.10)$ & $37.3(10.61)$ & $33.3(7.50)$ & 12.41 & 0.14 & $(0.06,0.26)$ \\
\hline SF-8 MCS & $50.4(9.43)$ & $45.6(11.82)$ & $44.4(11.33)$ & 8.15 & 0.09 & $(0.02,0.20)$ \\
\hline Cardiovascular & $(n=469)$ & $(n=107)$ & $(n=35)$ & & & \\
\hline QDIS-7 & $48.5(8.83)$ & $58.9(6.66)$ & $65.6(5.60)$ & 123.29 & 1.00 & \\
\hline SF-8 PCS & $41.8(10.25)$ & $34.2(8.55)$ & $30.4(7.21)$ & 43.32 & 0.35 & $(0.24,0.50)$ \\
\hline SF-8 MCS & $49.8(9.70)$ & 46.5 (10.70) & $39.1(12.74)$ & 21.47 & 0.17 & $(0.07,0.30)$ \\
\hline Diabetes & $(N=870)$ & $(N=317)$ & $(N=58)$ & & & \\
\hline QDIS-7 & $45.3(6.42)$ & $51.5(7.21)$ & $59.0(5.85)$ & 196.01 & 1.00 & \\
\hline SF-8 PCS & $48.4(8.76)$ & 44.4 (9.93) & $40.6(11.03)$ & 36.59 & 0.19 & $(0.11,0.28)$ \\
\hline SF-8 MCS & $51.9(8.08)$ & $48.4(9.75)$ & $42.6(11.49)$ & 44.33 & 0.23 & $(0.13,0.34)$ \\
\hline Respiratory & $(N=1106)$ & $(N=297)$ & $(N=109)$ & & & \\
\hline QDIS-7 & 44.7 (7.10) & $56.4(6.71)$ & $64.3(7.07)$ & 622.23 & 1.00 & \\
\hline SF-8 PCS & $48.1(9.46)$ & $41.4(10.20)$ & $33.4(10.84)$ & 149.30 & 0.24 & $(0.18,0.30)$ \\
\hline SF-8 MCS & $49.5(9.34)$ & $46.4(11.65)$ & $42.2(12.06)$ & 32.74 & 0.05 & $(0.03,0.08)$ \\
\hline
\end{tabular}

Abbreviations: CKD chronic kidney disease

${ }^{\text {a }}$ Severity defined as Mild (None, Mild), Moderate, or Severe (Severe, Very Severe) in response to item How would you rate the severity of your < condition > in the past 4 weeks?

${ }^{\mathrm{b}}$ Relative validity (RV) is computed as the ratio of the comparator F-statistic over the QDIS-7 F-statistic

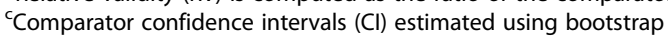

${ }^{d}$ QDIS-7 scored so a higher score equals worse health

${ }^{\mathrm{e}}$ Norm-based scoring of SF-8 Health Survey summary measures based on a representative probability sample of the US general household population surveyed in 2011 , norms (mean $=50, S D=10$ ) scored so a higher score equals better health

ratings within all five disease groups. QDIS-7 consistently had higher correlations with other disease-specific measures than with generic physical $(r=-0.43$ to -0.69 , median $=-0.52)$ and mental $(r=-0.38$ to -0.51 , median $=-0.44)$ summary measures.

\section{Responsiveness}

In longitudinal analyses, $59.4 \%$ reported the same preID disease status at 9-month follow-up and those who changed were more likely better $(24.6 \%)$ than worse (16.0\%). Table 7 compares mean changes in QDIS and physical and mental scores across five groups reporting different disease-specific outcomes. In support of the hypothesis that disease-specific QDIS measures are more responsive than generic measures, Table 7 shows a much higher F-ratio $(F=29.8, p<0.0001)$ for QDIS-7 (RV = 1.0) in comparison with generic physical $(F=14.2, p<0.0001)$ and mental $(F=2.1, \mathrm{NS})$ measures, and significantly lower $\mathrm{RV}$ estimates ( $\mathrm{RV}=0.47$ and 0.07 , respectively). This pattern of results, which supports QDIS responsiveness as a disease-specific measure, was replicated across pre-ID groups analyzed separately with one exception (equivalent QDIS and generic SF-8 PCS RV estimates for OA).

\section{Norms}

Norm-based descriptive statistics for five disease-specific severity levels for the combined pre-ID sample are documented in Additional file 7: Figure S4 for use in interpreting cross-sectional results. QDIS means and medians differed substantially and were ordered as hypothesized across severity levels. A noteworthy floor effect was observed only in the least severe (None) group.

\section{Discussion}

QDIS combines the strengths of two traditions within QOL measurement. It harnesses the precision and discriminability of disease-specific assessment with the comprehensiveness of generic QOL assessment. The result is an approach that differs from available disease-specific measures in noteworthy ways. First, and foremost, it 
Table 6 Correlations of QDIS-7 with disease-specific and generic measures, five disease groups

\begin{tabular}{llllll}
\hline Disease & $\mathrm{N}$ & Disease-specific severity & Deneric Physical $^{\mathrm{c}}$ & ${\text { Disease-specific } \text { QOL }^{\mathrm{b}}}^{\text {Generic Mental }^{\mathrm{C}}}$ \\
\hline Arthritis & 925 & 0.72 & 0.71 & -0.69 & -0.44 \\
CKD & 240 & 0.66 & 0.83 & -0.44 & -0.43 \\
Cardiovascular & 542 & 0.65 & $0.72,0.79$ & -0.52 & -0.51 \\
Diabetes & 695 & 0.54 & $0.72,0.72$ & -0.43 & -0.49 \\
Respiratory & 848 & 0.74 & 0.83 & -0.58 & -0.38 \\
\hline
\end{tabular}

QDIS-7 scored so a higher score equals worse health

Abbreviations: CKD chronic kidney disease

${ }^{\text {a }}$ Self-rating of disease severity (5 categories, None-Very Severe)

${ }^{b}$ Disease-specific QOL measures are Arthritis: Western Ontario and McMaster Universities Osteoarthritis Index (WOMAC ${ }^{\bullet}$ ) Total scale [6]; CKD: Kidney-Disease Quality of Life 36-item instrument (KDQOL-36 ${ }^{\mathrm{TM}}$ ) Burden scale [11]; Cardiovascular: Angina/MI-Seattle Angina Questionnaire Quality of Life scale [38] (first entry $N=275$ ) and CHF-Minnesota Living with Heart Failure ${ }^{\oplus}$ Questionnaire total scale [39] (second entry, $N=267$ ); Diabetes: Problem Areas in Diabetes Scale total scale [41] (first entry) and Diabetes Quality of Life measure total scale [40] (second entry); Respiratory: St. George's Respiratory Questionnaire total scale [7]. All diseasespecific measures are scored so a higher score equals worse health

'SF-8 Health Survey physical and mental component summary measures scored so a higher score equals better health

standardizes both content and scoring across diseases, which to our knowledge has never been done before. Second, disease-specific QOL impact content representation has been increased to be on a par with that of comprehensive generic QOL measures. Third, in support of interpreting QDIS as a disease-specific measure, results from this initial evaluation showed that QDIS discriminated across disease severity levels and responded when groups differed in disease-specific outcomes at 9 months markedly better than generic measures. Fourth, QDIS is the first disease-specific measure standardized across diseases and normed in a representative sample of the chronically ill general population.

Standardization began with the content of the same 49 items, differing only in disease-specific attribution. Scoring of a single summary measure was based upon formal tests that confirmed a unidimensional model, consistent with previously-reported results for other disease-specific summary measures [13, 29, 43-45]. Further, the equivalence of parameters across disease groups was sufficient to justify their standardization, and very high $(r>0.99)$ agreement was observed between disease-specific and standardized IRT-based score estimates. Subsequently, an independent test of standardized versus study-specific QDIS-7 item parameters estimated for acute coronary syndrome (ACS) patients showed sufficient IRT invariance to warrant use of standardized parameters in studies comparing QOL impact for ACS and other conditions [17]. In addition to very high $(r=0.99)$ scale-level agreement between ACS-specific and standardized score estimates, this replication is noteworthy because ACS data were collected by telephone interviews versus Internet-based, self-administrations in DICAT.

What is the importance of leveraging broader generic QOL content for purposes of measuring disease-specific impact? By definition, content validity is greater with more complete representation of relevant content areas $[3,8,68,69]$. Furthermore, representing multiple content areas in QDIS probably results in a more interesting survey administration, in contrast to answering items about the same content multiple times [70]. Respondents also may identify more with one QOL impact description than another. If so, multiple distinct descriptions may be more likely to capture disease impact and expand the usefulness of information available for interpreting research results and for clinicians and patients to discuss.

Like all measures relying on disease-specific attributions, QDIS assumes that respondents with multiple

Table 7 Responsiveness of QDIS-7 and generic measures in comparisons across groups differing in self-evaluated outcomes during 9-month follow-up, all diseases combined

\begin{tabular}{|c|c|c|c|c|c|c|c|c|}
\hline \multirow[t]{3}{*}{ Measure } & \multicolumn{5}{|c|}{ Mean change score by self-evaluated outcome ${ }^{a}$} & \multirow[t]{3}{*}{ F-ratio } & \multirow[t]{3}{*}{$R V^{b}$} & \multirow[t]{3}{*}{$95 \% \mathrm{Cl}^{\mathrm{C}}$} \\
\hline & Much better & Somewhat better & Same & Somewhat worse & Much worse & & & \\
\hline & $(N=244)$ & $(N=245)$ & $(N=1181)$ & $(N=282)$ & $(N=37)$ & & & \\
\hline${\mathrm{QDIS}-7^{\mathrm{d}}}^{2}$ & -2.76 & -0.04 & 1.29 & 3.20 & 5.87 & 29.80 & 1.00 & - \\
\hline SF-8 PCS ${ }^{d}$ & 1.36 & -0.71 & -0.28 & -3.22 & -4.98 & 14.15 & 0.47 & $(0.24,0.85)$ \\
\hline SF-8 MCS ${ }^{d}$ & 1.33 & -0.47 & 0.14 & -0.33 & -0.91 & 2.06 & 0.07 & $(0.00,0.15)$ \\
\hline
\end{tabular}

${ }^{a}$ Self-evaluated change groups were defined as much better, somewhat better, about the same, somewhat worse, or much worse now in response to the question: "Compared to nine months ago, how much better or worse is your < DISEASE > now?", where DISEASE was the pre-ID condition

${ }^{b}$ Relative validity (RV) is computed as the ratio of the comparator F-statistic over the largest F-statistic for that comparison

'Comparator confidence intervals $(\mathrm{Cl})$ estimated using bootstrap

${ }^{\mathrm{d}}$ Norm-based scoring of all measures based on US general population norms (mean $=50, \mathrm{SD}=10$ ). QDIS-7 scored so a higher score equals worse health; SF-8 scored so a higher score equals better health 
chronic conditions (MCC) can validly differentiate the specific impact of one disease from that of others, a rarely tested assumption. Although our initial results comparing measures differing in attributions to a specific disease versus health in general support this assumption, current study methods did not test it directly. For example, the greater validity and responsiveness observed for QDIS over generic measures could reflect the impact of a comorbid condition. This crucial issue has been addressed in a parallel study [71] of adults with MCC. Results from multitrait-multimethod (MTMM) tests of construct validity [72] based on analysis of DICAT data for 4480 respondents with MCC strongly support the assumption that adults can validly differentiate the specific impact of one condition from that of others. Briefly, results from MTMM tests of up to 26 comorbid conditions within each of eight pre-ID conditions demonstrated convergent validity; correlations among three methods (QDIS, severity, symptoms) of measuring the same condition were substantial $(r=0.38$ to 0.84 , median $=0.53)$ across pre-ID conditions. In contrast, as hypothesized for discriminating measures, correlations between methods of measuring different conditions were significantly lower than corresponding convergent correlations in 833 of 924 (90.2 \%) tests; exceptions were most often observed for comorbid conditions in the same clinical area. It follows from these results and those reported in this paper that the standardized QDIS approach based on attributions to specific diseases warrants further tests of its use in quantifying and comparing each disease as well as aggregating scores to estimate the cumulative burden of multiple diseases, thereby addressing an important measurement gap [69].

Historically, an advantage of generic QOL measures over disease-specific measures has been the availability of general population norms for use in interpreting generic outcomes. However, this tradeoff is unnecessary to the extent that disease-specific populations can be defined and sampled. A practical limitation to widespread standardization and norming has been the many different disease-specific measures. By standardizing both content and scoring, QDIS enables a practical approach to the norm-based interpretation of disease-specific QOL impact throughout the chronically ill population. To make norm-based interpretation easier, scores were transformed to have a mean of 50 and SD of 10 in the US chronically ill household population using a T-score transformation, such as that adopted for the SF-36 [73], SF-12 [74] and SF-8 [23] Health Surveys and PROMIS $^{\circ}$ [75]. By placing all disease-specific scores on the same QOL impact metric, clinicians can better understand the implications of differences in disease severity with a level of specificity that is not possible with a generic measure and researchers can aggregate patient scores for predictive and outcome analyses across diseases.

\section{Modeling issues}

Considerable art is involved in the application of measurement theory and methods to the measurement of QOL impact. Accordingly, different interpretation of the multiple criteria applied here or the application of different methods might have led to different selections of items for the 7-item static form (QDIS-7) and the 25-item bank. In our Methods and Results sections, we have attempted to explain the logic that was applied in considering itemspecific evidence of many types. To facilitate other choices and replications in other disease groups, we have documented results for the entire 49-item bank.

The strong support for a 1-factor model observed in every disease group studied is consistent with previous findings for QOL items making attributions to specific conditions $[13,29,43]$. It is also in sharp contrast to measurement models for generic items and scales that confirm conceptually- and empirically-distinct subdomains and higher-order physical and mental factors [73, 76]. In marked contrast, it appears that adults asked to focus on a specific condition make QOL attributions more on the basis of differences in the overall severity and QOL impact of each condition and less on the basis of the different aspects of QOL (e.g., physical, emotional, role/social).

QDIS scored using the classical method of summated ratings [77] and IRT item parameter estimates correlated very highly throughout the score range in every disease group. Hence, scores estimated using both methods can be transformed (mean $=50, S D=10$ ) throughout the chronically ill US population. However, well-documented and noteworthy advantages of IRT models, such as more accurate CATbased estimates of individual scores at every level of theta, would be lost in the absence of IRT-based item parameters.

\section{Alternate forms}

Because electronic data capture is not always possible, the QDIS-7 fixed-length form was evaluated in parallel with CAT as in previous studies [57, 62, 65]. In support of the direct comparability of norm-based scoring of both approaches, the correlation between the static QDIS-7 and QDIS-CAT-6 scores ranged from 0.97 to 0.98 across the five disease groups studied and mean estimates were nearly identical across measures. We also extended the adaptive logic at the 9-month follow-up by using CAT only for those patients suspected of scoring in the most impaired range and relying on a noisier but unbiased single-item QDIS estimate (QL1) for those showing lower or no impact. The gains in efficiency included a nearly $80 \%$ reduction in respondent burden while still achieving the hypothesized superiority in responsiveness over generic outcome measures. This alternative to static shortform and routine fixed-length CAT measurement warrants further study, particularly for purposes of individual-level 
applications requiring greater reliability than group-level comparisons.

The single-item QDIS estimate (QL1) correlated 0.89 with the 49-item bank theta score and produces unbiased (although coarse) estimates of disease-group means across population surveys and large-group studies if scored using the recommended T-score transformation. This singleitem measure has also been shown to achieve convergent and discriminant validity among adults with multiple chronic conditions (MCC). Therefore, it may provide a practical pathway to a standard global QOL impact measure that uses disease-specific attribution to measure total MCC impact. Such an aggregate measure may be a valid addition to the toolkit for adjusting for differences in case mix in observational studies of patient-reported outcomes.

\section{Limitations}

Although replications across diseases are rare for new approaches to QOL measurement, it is a limitation that only nine conditions in five disease groups were the basis of initial QDIS development and validation. The consistency of results across diseases suggests that the findings are likely to generalize to other physical conditions. Analyses of subgroups-OA and RA within arthritis, asthma and COPD within respiratory, and angina, MI and CHF within cardiovascular-replicated findings reported here, although with some limitations due to smaller samples. However, all of the pre-ID disease groups were physical health conditions, and the omission of any pre-ID mental health groups is a noteworthy limitation of the current study. Self-reported depression, not analyzed here, was prevalent (13-26\%) across the pre-ID groups and was shown elsewhere to be validly measured by QDIS as a comorbid condition [71]. We recommend extension of future studies to include mental and other physical diseases.

Another potential limitation is reliance entirely on selfreports for disease severity and legacy disease-specific measures. Although self-report methods have been useful in validation $[16,75]$ results may have been different if "criteria" had been based on independent clinical evaluations. Although any self-report bias is unlikely to account for the superior discriminant validity observed for QDIS over generic measures, QDIS should be evaluated in relation to more objective clinical criteria, which are also likely to make interpretation guidelines more useful clinically. Examples of more independent clinical validation include a recent trial using QDIS with attribution to smoking; QDIS correlated substantially higher with four biomarkers of smoking exposure [78] and discriminated between current and former smokers much better [79] than generic SF-36v2 ${ }^{\circ}$ Health Survey measures. Similarly, QDIS with attribution to kidney disease discriminated across clinically-defined stages of CKD better than the SF-12 [65].
The lack of new patient involvement in selecting and modifying QDIS items is a noteworthy potential limitation of the current study. Although QDIS item selection and modification benefited from previous qualitative studies of phrases in the QDIS items, it is possible that de novo qualitative studies would lead to further improvements, if changes in attributions from health to a specific condition materially change item meaning or clarity. To what extent does changing the attribution of QOL impact from health in general to a specific disease require additional patient involvement in qualitative evaluation [80]? The advantage of more such evidence is the opportunity to add findings from qualitative studies to the rich array of evidence in Table 2 and to better understand the inevitable tradeoffs in choosing among items. However, single-disease studies often ignore the presence of multiple chronic conditions. Accordingly, we recommend that qualitative research be conducted systematically among patients with MCC for QDIS and other measures that use disease-specific attributions.

\section{Recommendations for future research}

In addition to the issues noted above, the psychometric properties of items selected for administration in static QDIS short forms or by CAT warrant further study. Our observation that some of the poorest fitting items in terms of traditional fit statistics were the most predictive and most utilized by CAT led us to consider multiple criteria in selecting items for QDIS-7 and the 25-item bank, including information functions at the most prevalent score levels. Further, more in-depth tests of itemand scale-level parameter invariance analogous to the ACS study [17] are likely to be informative.

To the extent that current study findings are generalizable to other conditions for which comprehensive disease-specific QOL measures are not readily available, QDIS may enable a substantial short-cut to achieving disease-specific QOL impact estimates. Examples include applications to rare diseases and the evaluations of orphan drugs. Patient and clinician input in establishing clear and familiar terminology for disease-specific attribution would be a prerequisite and assumptions underlying scoring, reliability and validity would need to be evaluated, as always should be done for a new disease application of a standardized measure. However, for conditions lacking a summary QOL impact measure, QDIS may be a practical solution that does not require years of development and considerable resources.

\section{Conclusions}

Overall, this pursuit of disease-specific QOL measurement innovation appears to be on the right track toward filling the conceptual and methodological gaps between disease-specific symptoms that do not measure quality 
of life and generic QOL measures that do not measure disease-specific outcomes. By integrating the richness of generic QOL item content with disease-specific attributions and by standardizing scoring metrics, QDIS achieves some of the advantages of both disease-specific and generic PRO measurement traditions. The result is a new method for comparing outcomes across diseases while retaining the advantages of disease-specific measures. The broader representation of item content in QDIS may expand knowledge about the various ways in which specific diseases impact patients' quality of life and the benefits of their treatment. To facilitate its use, information about QDIS and permission to use it for scholarly and commercial applications is available at www.jwrginc.com.

\section{Additional files}

Additional file 1: Table S1. Comparison of relative validity (RV) of QDIS (7-item Static and 6-item CAT) and generic measures in discriminating across severity levels, five disease groups. (PDF $104 \mathrm{~kb}$ )

Additional file 2: Table S2. Correlations of QDIS-7 (7-item Static and 6-item CAT) with disease-specific and generic measures, five disease groups. (PDF $155 \mathrm{~kb}$ )

Additional file 3: Figure S1. Plots of QDIS disease-specific and standardized slopes. (PDF $123 \mathrm{~kb}$ )

Additional file 4: Figure S2. Plots of QDIS disease-specific and standardized thresholds. (PDF $122 \mathrm{~kb}$ )

Additional file 5: Table S3. Correlations among disease-specific and standardized IRT parameters ${ }^{\mathrm{a}}$. (PDF $90.5 \mathrm{~kb}$ )

Additional file 6: Figure S3. Plots of QDIS theta scores estimated using disease-specific and standardized parameters. (PDF 196 kb)

Additional file 7: Figure S4. Plot of QDIS-7 medians and ranges for standardized scores and percentile ranks by severity level, all disease groups combined. (PDF $130 \mathrm{~kb}$ )

\section{Abbreviations}

ACS, acute coronary syndrome; CAT, computerized adaptive testing; CFA, confirmatory factor analysis; $\mathrm{CFI}$, coefficient of fit index; CKD, chronic kidney disease; DICAT, Computerized Adaptive Assessment of Disease Impact project; DIF, differential item functioning; GPCM, generalized partial credit model; ICC, intraclass correlation coefficient; IRT, item response theory; MCC, multiple chronic conditions; MCS, mental component summary; MGCFA, multi-group confirmatory factor analysis; MOS, Medical Outcomes Study; OLR, ordinal logistic regression; PCS, physical component summary; PRO, patient-reported outcome; PROMIS, Patient Reported Outcomes Measurement Information System; QDIS, Quality of life Disease Impact Scale; QDIS-7, 7-item short-form of QDIS; QDIS-CAT-6, 6-item adaptive short form of QDIS; QOL, quality of life; RMSEA, root mean square error of approximation; RV, relative validity; SF-12, SF-12 Health Survey; SF-36, SF-36 Health Survey; SF-8, SF-8 Health Survey; WLSMV, weighted least squares estimator with mean and variance adjustment.

\section{Acknowledgements}

The authors acknowledge the prior administrative assistance of Rosemarie Boulanger and ongoing technological management of Josh Ryan at JWRG, the support of GfK USA (formerly Knowledge Networks) in managing the complicated DICAT study design and data collection process, and the very helpful comments from anonymous reviewers. Preliminary results from studies of QDIS were presented at the $19^{\text {th }}$ Annual Conference of the International Society of Quality of Life Research in Budapest, Hungary; the $16^{\text {th }}$ Annual European Congress of the International Society for Pharmacoeconomics and Outcomes Research in Dublin, Ireland; and the 22nd Annual Conference of the International Society for Quality of Life Research (ISOQOL), Vancouver, British Columbia, Canada. QDIS is a registered trademark of JWRG. SF- $36^{\oplus}, \mathrm{SF}^{-} 36 \mathrm{~V} 2^{\circledR}$ and $\mathrm{SF}-12^{-}$are registered trademarks of the Medical Outcomes Trust. SF-8 ${ }^{\text {TM }}$ is a trademark of QualityMetric Incorporated. PROMIS ${ }^{\oplus}$ is a registered trademark of the U.S. Department of Health and Human Services. All other trademarks are the property of their respective owners.

\section{Funding}

QDIS development, evaluation and preparation of this paper were supported by a National Institute on Aging SBIR grant (R44-AG025589, J Ware, PI).

Preparation of this paper also was supported by AHRQ grant R21-HS023117

(J Ware, PI) and by John Ware Research Group from its own research funds.

\section{Authors' contributions}

JW conceived of and designed the DICAT study. JW and RG participated in data collection. Data analysis and interpretation were performed by JW, BG, $\mathrm{RG}$ and ND. All authors contributed to writing and reviewing the manuscript and approved the final version.

\section{Competing interests}

Dr. Ware is Chief Science Officer and shareholder of the John Ware Research Group (JWRG), which has been funded by NIH Small Business Innovation Research grants and unrestricted industry grants. Dr. Gandek is a current employee and shareholder of JWRG. Dr. Guyer is a former employee of JWRG.

\section{Ethics approval and consent to participate}

All studies involving human participants were performed in accordance with the ethical standards of the 1964 Helsinki declaration and its later amendments. The DICAT study was approved by the New England Institutional Review Board (NEIRB\# 09-062).

\section{Author details}

1John Ware Research Group, 10 Wheeler Court, Watertown, MA 02472, USA. ${ }^{2}$ Department of Quantitative Health Sciences, University of Massachusetts Medical School, Worcester, MA, USA. ${ }^{3}$ Measured Progress, Dover, NH, USA.

Received: 17 January 2016 Accepted: 6 May 2016

Published online: 02 June 2016

\section{References}

1. Wiebe S, Guyatt G, Weaver B, Matijevic S, Sidwell C. Comparative responsiveness of generic and specific quality-of-life instruments. J Clin Epidemiol. 2003;56(1):52-60.

2. Wilson IB, Cleary PD. Linking clinical variables with health-related quality of life. A conceptual model of patient outcomes. JAMA. 1995;273(1):59-65.

3. U.S. Department of Health and Human Services, Food and Drug Administration. Guidance for industry - patient-reported outcome measures: use in medical product development to support labeling claims. Rockville, MD: Food and Drug Administration; 2009.

4. Frendl DM, Ware Jr JE. Patient-reported functional health and well-being outcomes with drug therapy: a systematic review of randomized trials using the SF-36 Health Survey. Med Care. 2014;52(5):439-45.

5. Contopoulos-loannidis DG, Karvouni A, Kouri I, loannidis JP. Reporting and interpretation of SF-36 outcomes in randomised trials: systematic review. BMJ. 2009;338:a3006.

6. Bellamy N, Buchanan WW, Goldsmith CH, Campbell J, Stitt LW. Validation study of WOMAC: a health status instrument for measuring clinically important patient relevant outcomes to antirheumatic drug therapy in patients with osteoarthritis of the hip or knee. J Rheumatol. 1988;15(12):1833-40.

7. Jones PW, Quirk FH, Baveystock CM, Littlejohns P. A self-complete measure of health status for chronic airflow limitation. The St. George's Respiratory Questionnaire. Am Rev Respir Dis. 1992;145(6):1321-7.

8. Ware Jr JE. Standards for validating health measures: definition and content. J Chronic Dis. 1987:40(6):473-80.

9. Patrick DL, Deyo RA. Generic and disease-specific measures in assessing health status and quality of life. Med Care. 1989;27(3 Suppl):S217-32.

10. Sprangers MA, Cull A, Bjordal K, Groenvold M, Aaronson NK. The European Organization for Research and Treatment of Cancer. Approach to quality of life assessment: guidelines for developing questionnaire modules. Qual Life Res. 1993;2(4):287-95. 
11. Hays RD, Kallich JD, Mapes DL, Coons SJ, Carter WB. Development of the Kidney Disease Quality of Life (KDQOL) instrument. Qual Life Res. 1994;3(5): 329-38

12. Kosinski M, Bayliss MS, Bjorner JB, Ware Jr JE, Garber WH, Batenhorst A, Cady R, Dahlof CG, Dowson A, Tepper S. A six-item short-form survey for measuring headache impact: the HIT-6. Qual Life Res. 2003;12(8):963-74.

13. Webb SM, Badia X, Barahona MJ, Colao A, Strasburger CJ, Tabarin A, van Aken MO, Pivonello R, Stalla G, Lamberts SW, Glusman JE. Evaluation of health-related quality of life in patients with Cushing's syndrome with a new questionnaire. Eur J Endocrinol. 2008;158(5):623-30.

14. Bergner M, Bobbitt RA, Carter WB, Gilson BS. The Sickness Impact Profile: development and final revision of a health status measure. Med Care. 1981; 19(8):787-805.

15. Ware Jr JE, Sherbourne CD. The MOS 36-item short-form health survey (SF-36). I. Conceptual framework and item selection. Med Care. 1992;30(6):473-83.

16. Stewart AL, Ware Jr JE. Measuring functioning and well-being: the Medical Outcomes Study approach. Durham: Duke University Press; 1992.

17. Deng N, Anatchkova MD, Waring ME, Han KT, Ware Jr JE. Testing item response theory invariance of the standardized Quality-of-life Disease Impact Scale (QDIS ${ }^{\circledR}$ ) in acute coronary syndrome patients: differential functioning of items and test. Qual Life Res. 2015;24:1809-22.

18. Ware Jr JE, Guyer R, Harrington M, Boulanger R. Evaluation of a more comprehensive survey item bank for standardizing disease-specific impact comparisons across chronic conditions. Qual Life Res. 2012;21(1 Suppl):27-8.

19. Ware Jr JE, Harrington M, Guyer R, Boulanger R. A system for integrating generic and disease-specific patient-reported outcome (PRO) measures. Mapi Research Institute Patient Reported Outcomes Newsletter 2012;48:1-4.

20. Ware Jr JE, Nelson EC, Sherbourne CD, Stewart AL. Preliminary tests of a 6item general health survey: a patient application. In: Stewart AL, Ware JE, editors. Measuring functioning and well-being: the Medical Outcomes Study approach. Durham: Duke University Press; 1992. p. 291-303.

21. Martin ML, Patrick DL, Gandra SR, Bennett AV, Leidy NK, Nissenson AR, Finkelstein FO, Lewis EF, Wu AW, Ware Jr JE. Content validation of two SF-36 subscales for use in type 2 diabetes and non-dialysis chronic kidney disease related anemia. Qual Life Res. 2011;20(6):889-901.

22. Bruce B, Fries JF, Ambrosini D, Lingala B, Gandek B, Rose M, Ware Jr JE. Better assessment of physical function: item improvement is neglected but essential. Arthritis Res Ther. 2009:11(6):R191.

23. Ware Jr JE, Kosinski M, Dewey JE, Gandek B. How to score and interpret single-item health status measures: a manual for users of the SF-8 Health Survey. Lincoln, RI: QualityMetric Incorporated; 2001.

24. Ware Jr JE, Brook RH, Davies-Avery A, Williams KN, Stewart AL, Rogers WH, Donald CA, Johnston SA. Conceptualization and Measurement of Health for Adults in the Health Insurance Study: Volume I, Model of Health and Methodology, R-1987/1-HEW. Santa Monica: The Rand Corporation; 1980.

25. Stewart AL, Ware Jr JE, Brook RH, Davies-Avery A. Conceptualization and Measurement of Health for Adults in the Health Insurance Study: Volume II, Physical Health in Terms of Functioning, R-1987/2-HEW. Santa Monica: The Rand Corporation; 1978.

26. Ware JE, Johnston SA, Davies-Avery A, Brook RH. Conceptualization and Measurement of Health for Adults in the Health Insurance Study: Volume III Mental Health, R-1987/3-HEW. Santa Monica: The Rand Corporation; 1979.

27. Donald CA, Ware Jr JE, Brook RH, Davies-Avery A. Conceptualization and Measurement of Health for Adults in the Health Insurance Study: Volume IV, Social Health, R-1987/4-HEW. Santa Monica: The Rand Corporation; 1978.

28. Ware Jr JE, Davies-Avery A, Donald CA. Conceptualization and Measurement of Health for Adults in the Health Insurance Study: Volume V, General Health Perceptions, R-1987/5-HEW. Santa Monica: The Rand Corporation; 1978.

29. Bjorner JB, Kosinski M, Ware Jr JE. Calibration of an item pool for assessing the burden of headaches: an application of item response theory to the Headache Impact Test (HIT). Qual Life Res. 2003;12(8):913-33.

30. Kosinski M, Bjorner JB, Ware Jr JE, Sullivan E, Straus WL. An evaluation of a patient-reported outcomes found computerized adaptive testing was efficient in assessing osteoarthritis impact. J Clin Epidemiol. 2006:59(7):715-23.

31. Richardson MM, Saris-Baglama RN, Anatchkova MD, Stevens LA, Miskulin DC, Turner-Bowker DM, Meyer KB, Ware Jr JE. Patient experience of Chronic Kidney Disease (CKD): results of a focus group study. Orlando: Annual National Kidney Foundation Spring Clinical Meeting; 2007.

32. Turner-Bowker DM, Saris-Baglama RN, Derosa MA, Paulsen CA, Bransfield CP. Using qualitative research to inform the development of a comprehensive outcomes assessment for asthma. Patient. 2009;2(1):269-82.
33. Turner-Bowker DM, Saris-Baglama RN, Derosa MA, Paulsen CA. Cognitive testing and readability of an item bank for measuring the impact of headache on health-related quality of life. Patient. 2012;5(2):89-99.

34. Paz SH, Liu H, Fongwa MN, Morales LS, Hays RD. Readability estimates for commonly used health-related quality of life surveys. Qual Life Res. 2009; 18(7):889-900.

35. AAPOR Standards Committee Task Force. Research Synthesis: AAPOR Report on Online Panels. Public Opin Q. 2010;74:711-81.

36. Fowler Jr FJ, Gerstein BS, Barry MJ. How patient centered are medical decisions? Results of a national survey. JAMA Intern Med. 2013;173(13):1215-21.

37. The American Association for Public Opinion Research. Standard Definitions: Final Dispositions of Case Codes and Outcome Rates for Surveys. 8th edition: AAPOR; 2015.

38. Spertus JA, Winder JA, Dewhurst TA, Deyo RA, Prodzinski J, McDonell M, Fihn SD. Development and evaluation of the Seattle Angina Questionnaire: a new functional status measure for coronary artery disease. J Am Coll Cardiol. 1995:25(2):333-41.

39. Rector TS, Kubo SH, Cohn JN. Patients' self-assessment of their congestive heart failure: Content, reliability, and validity of a new measure, the Minnesota Living with Heart Failure questionnaire. Heart Fail. 1987;3:198-209.

40. Jacobson AM, de Groot M, Samson JA. The evaluation of two measures of quality of life in patients with type I and type II diabetes. Diabetes Care. 1994;17(4):267-74

41. Welch GW, Jacobson AM, Polonsky WH. The Problem Areas in Diabetes Scale. An evaluation of its clinical utility. Diabetes Care. 1997;20(5):760-6.

42. Brown TA. Confirmatory Factor Analysis for Applied Research. 2nd ed. New York: Guilford Press; 2015.

43. de Boer AG, Spruijt RJ, Sprangers MA, de Haes JC. Disease-specific quality of life: is it one construct? Qual Life Res. 1998;7(2):135-42.

44. Ware Jr JE, Kemp JP, Buchner DA, Singer AE, Nolop KB, Goss TF. The responsiveness of disease-specific and generic health measures to changes in the severity of asthma among adults. Qual Life Res. 1998:7(3):235-44.

45. Pakhale S, Wood-Dauphinee S, Spahija J, Collet JP, Maltais F, Bernard S, Baltzan M, Rouleau M, Bourbeau J. Combining both generic and diseasespecific properties: development of the McGill COPD quality of life questionnaire. COPD. 2011:8(4):255-63.

46. Muthén LK, Muthén BO. Mplus User's Guide. Sixth Edition. Los Angeles: Muthén \& Muthén; 1998-2010.

47. Cook KF, Kallen MA, Amtmann D. Having a fit: impact of number of items and distribution of data on traditional criteria for assessing IRT's unidimensionality assumption. Qual Life Res. 2009;18(4):447-60.

48. Cheung GW, Rensvold RB. Evaluating goodness-of-fit indexes for testing measurement invariance. Struct Equ Modeling. 2002;9(2):233-55.

49. Reeve BB, Hays RD, Bjorner JB, Cook KF, Crane PK, Teresi JA, Thissen D, Revicki DA, Weiss DJ, Hambleton RK, Liu H, Gershon R, Reise SP, Lai JS, Cella D, PROMIS Cooperative Group. Psychometric evaluation and calibration of health-related quality of life item banks: plans for the Patient-Reported Outcomes Measurement Information System (PROMIS). Med Care. 2007:45(5 Suppl 1):S22-31.

50. Zumbo BD. A Handbook on the Theory and Methods of Differential Item Functioning (DIF): Logistic Regression Modeling as a Unitary Framework for Binary and Likert-Type (Ordinal) Item Scores. Ottawa: Directorate of Human Resources Research and Evaluation, Department of National Defense: 1999.

51. Choi SW, Gibbons LE, Crane PK. lordif: An R package for detecting differential item functioning using iterative hybrid ordinal logistic regression/item response theory and Monte Carlo simulations. J Stat Softw. 2011;39(8):1-30.

52. Nagelkerke NJ. A note on a general definition of the coefficient of determination. Biometrika. 1991;78:691-2.

53. Crane PK, Gibbons LE, Ocepek-Welikson K, Cook K, Cella D, Narasimhalu K, Hays RD, Teresi JA. A comparison of three sets of criteria for determining the presence of differential item functioning using ordinal logistic regression. Qual Life Res. 2007;16 Suppl 1:69-84.

54. Muraki E. Generalized partial credit model. In: van der Linden W, Hambleton RK, editors. Handbook of Modern Item Response Theory. New York: Springer; 1997. p. 153-64.

55. Ware Jr JE, Bjorner JB, Kosinski M. Practical implications of item response theor and computerized adaptive testing: a brief summary of ongoing studies of widely used headache impact scales. Med Care. 2000;38(9 Suppl):I173-82.

56. Bjorner JB, Kosinski M, Ware Jr JE. Using item response theory to calibrate the Headache Impact Test (HIT) to the metric of traditional headache scales. Qual Life Res. 2003;12(8):981-1002. 
57. Rose M, Bjorner JB, Becker J, Fries JF, Ware Jr JE. Evaluation of a preliminary physical function item bank supported the expected advantages of the Patient-Reported Outcomes Measurement Information System (PROMIS). J Clin Epidemiol. 2008;61(1):17-33.

58. Guyer R, Thompson N. Xcalibre ${ }^{\mathrm{TM}}$ 4: IRT Item Parameter Estimation Software. Saint Paul, MN: Assessment Systems Corporation; 2011.

59. Orlando M, Thissen D. Likelihood-based item-fit indices for dichotomous item response theory models. Appl Psychol Meas. 2000;24:50-64.

60. Glas CAW. Testing fit to IRT models for polytomously scored items. In: Nering ML, Ostini R, editors. Handbook of Polytomous Item Response Theory Models. New York: Routledge; 2010. p. 185-208.

61. Liang T, Han KT, Hambleton RK. ResidPlots-2: Computer software for IRT graphical residual analyses. Appl Psychol Meas. 2009;33:411-2.

62. Ware Jr JE, Kosinski M, Bjorner JB, Bayliss MS, Batenhorst A, Dahlof CG, Tepper S, Dowson A. Applications of computerized adaptive testing (CAT) to the assessment of headache impact. Qual Life Res. 2003;12(8):935-52.

63. Cronbach $\sqcup$. Coefficient alpha and the internal structure of tests. Psychometrika. 1951;16(3):297-334.

64. Kerlinger FN. Foundations of Behavioral Research. New York: Holt, Rinehart, and Winston; 1964.

65. Deng N, Allison JJ, Fang HJ, Ash AS, Ware Jr JE. Using the bootstrap to establish statistical significance for relative validity comparisons among patient-reported outcome measures. Health Qual Life Outcomes. 2013;11:89.

66. Ware Jr JE, Gandek B, Franklin P, Lemay C. Cutting edge solutions to improving the efficiency of PRO measurement: from real-data simulations to pilot testing before and after total joint replacement in a national registry. Qual Life Res. 2015;24(1 Suppl):60.

67. U.S. Bureau of the Census. Current Population Survey (CPS) [http://www. census.gov/cps/]. Accessed 2 Oct 2015.

68. Nunnally JC, Bernstein IH. Psychometric Theory. 3rd ed. New York: Mc-Graw Hill; 1994.

69. Working Group on Health Outcomes for Older Persons with Multiple Chronic Conditions. Universal health outcome measures for older persons with multiple chronic conditions. J Am Geriatr Soc. 2012;60(12):2333-41.

70. Deng N, Guyer R, Ware Jr JE. Energy, fatigue or both? A bifactor modeling approach to the conceptualization and measurement of vitality. Qual Life Res. 2015;24:81-93.

71. Ware Jr JE, Gandek B, Allison J. The validity of disease-specific quality of life attributions among adults with multiple chronic conditions. Int I Stat Med Res. 2016;5(1 (Special Issue)):17-40.

72. Campbell DT, Fiske DW. Convergent and discriminant validation by the multitrait-multimethod matrix. Psychol Bull. 1959:56(2):81-105.

73. Ware Jr JE, Kosinski M, Bayliss MS, McHorney CA, Rogers WH, Raczek A. Comparison of methods for the scoring and statistical analysis of SF-36 health profile and summary measures: summary of results from the Medical Outcomes Study. Med Care. 1995;33(4 Suppl):AS264-79.

74. Ware Jr JE, Kosinski M, Keller SD. A 12-Item Short-Form Health Survey: construction of scales and preliminary tests of reliability and validity. Med Care. 1996;34(3):220-33.

75. Cella D, Riley W, Stone A, Rothrock N, Reeve B, Yount S, N, Reeve B, Yount S, PROMIS Cooperative Group. The Patient-reported Outcomes Measurement Information System (PROMIS) developed and tested its first wave of adult self-reported health outcome item banks: 2005-2008. J Clin Epidemiol. 2010;63(11):1179-94.

76. Essink-Bot ML, Krabbe PF, Bonsel GJ, Aaronson NK. An empirical comparison of four generic health status measures. The Nottingham Health Profile, the Medical Outcomes Study 36-item Short-Form Health Survey, the COOP/ WONCA charts, and the EuroQol instrument. Med Care. 1997;35(5):522-37.

77. Likert R. A technique for the measurement of attitudes. Arch Psychol. 1932;140:5-55.

78. Ware Jr JE, Gandek B, Kulasekaran A, Guyer R. Evaluation of smoking-specific and generic quality of life measures in current and former smokers in Germany and the United States. Health Qual Life Outcomes. 2015;13:128.

79. Kulasekaran A, Proctor C, Papadopoulou E, Shepperd CJ, Guyer R, Gandek B, Ware Jr JE. Preliminary evaluation of a new German translated Tobacco Quality of Life Impact Tool to discriminate between healthy current and former smokers and to explore the effect of switching smokers to a reduced toxicant prototype cigarette. Nicotine Tob Res. 2015;17(12):1456-64.

80. Magasi S, Ryan G, Revicki D, Lenderking W, Hays RD, Brod M, Snyder C, Boers M, Cella D. Content validity of patient-reported outcome measures: perspectives from a PROMIS meeting. Qual Life Res. 2012;21(5):739-46.

\section{Submit your next manuscript to BioMed Central and we will help you at every step:}

- We accept pre-submission inquiries

- Our selector tool helps you to find the most relevant journal

- We provide round the clock customer support

- Convenient online submission

- Thorough peer review

- Inclusion in PubMed and all major indexing services

- Maximum visibility for your research

Submit your manuscript at www.biomedcentral.com/submit 